\title{
Hormonal Regulation of Postnatal Growth in Children Born Small for Gestational Age
}

\author{
S. Cianfarani C. Ladaki C. Geremia \\ 'Rina Balducci' Centre of Paediatric Endocrinology, Department of Public Health and Cell Biology, \\ Tor Vergata University, Rome, Italy
}

\section{Key Words}

Growth hormone - Hypothalamic-pituitary-adrenal axis • Insulin-like growth factor - Small for gestational age •

Thyroid

\begin{abstract}
Children born small for gestational age (SGA) are at high risk of permanent short stature, with approximately $10 \%$ continuing to have stature below the third centile throughout childhood and adolescence and into adulthood. The mechanisms involved in catch-up growth, and those that prevent catch-up growth, are still unknown. To date, no reliable anthropometric or endocrine parameter predictive of postnatal catch-up growth has been identified. However, subtle abnormalities in the growth hormone-insulin-like growth factor axis, the hypothalamic-pituitary-adrenal axis and thyroid function have been described, and a mechanism involving intrauterine programming of hypothalamic-pituitary function has been proposed.
\end{abstract}

Copyright (c) 2006 S. Karger AG, Basel

\section{Introduction}

Children born small for gestational age (SGA) are at high risk of becoming short adults. Although most children born SGA show catch-up growth in the first 2 years of life, approximately $10 \%$ will continue to have stature below the 3rd centile throughout childhood and adolescence and into adulthood [1]. To date, however, the mechanisms linking intrauterine growth retardation (IUGR) to postnatal short stature are still unknown [2]. It is known that birth length is an important predictor of final height [3-5]. Consistent with this, we have recently found a close correlation between birth length and catchup growth expressed as height corrected for target height (fig. 1). However, the endocrine mechanisms linking preand postnatal growth remain undetermined.

The first months of postnatal life seem to be crucial for the growth outcome of individuals born SGA, as most catch-up growth usually occurs during this relatively narrow time window. Subtle abnormalities of the growth hormone (GH)-insulin-like growth factor (IGF) axis, the hypothalamic-pituitary-adrenal axis and thyroid function have been described, and intrauterine programming of hypothalamic-pituitary function has been proposed. This review will highlight current understanding of the endocrine control of postnatal growth in children born SGA.

\section{GH Secretion}

Neonates born SGA show increased levels of GH [2, $6,7]$. This finding, together with that of reduced IGF-I and IGF-binding protein-3 (IGFBP-3) concentrations, suggests that these newborns show GH insensitivity. This

\section{KARGER}

Fax +4161306 1234 E-Mail karger@karger.ch www.karger.com 


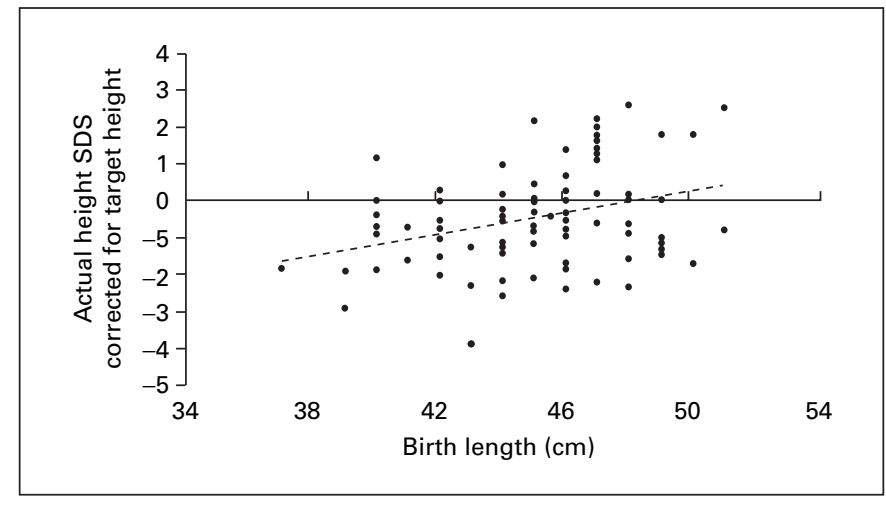

Fig. 1. Relationship between birth length and actual height corrected for target height in 81 children born SGA (mean age, $8.5 \pm$ 3.1 years). $r=0.33, p=0.002$.

alteration in the GH-IGF axis is transient, however, and normalization of GH, IGF-I and IGFBP-3 secretion occurs in early postnatal life [8].

Most short children born SGA show normal GH responses to stimulation tests and normal serum levels of IGF-I and IGFBP-3 [9]. A number of studies have focussed on spontaneous daily GH secretion in these individuals. Ackland et al. [10] found alterations in spontaneous GH secretion that were subsequently confirmed by de Waal et al. [11] and Boguszewski et al. [12]. The observed alterations consist of a high pulse frequency, attenuated pulse amplitude and relatively elevated interpulse concentrations of serum GH. In the study of de Waal et al. [11], nearly $60 \%$ of children born SGA showed an abnormal physiological daily secretion of $\mathrm{GH}$, characterized by decreased pulse amplitude. This altered pattern of spontaneous GH release was associated with reduced concentrations of IGF-I. Thieriot-Prevost et al. [13] reported that children born SGA with poor length gain during the first 12 months of life (length SD score $<-2$ at 1 year) had low levels of IGF-I. Together, these findings suggest that at least some children born SGA may have reduced or altered physiological GH secretion. These alterations are similar to those documented in adults with prolonged critical illness [14]. The abnormal pattern of GH secretion in children born SGA could therefore represent a neuroendocrine consequence of prolonged critical illness before birth [15]. Nevertheless, it should be noted that the assessment of spontaneous GH secretion is burdened by wide inter- and intra-individual variability, and that, although IGF-I and IGFBP-3 levels tend to be in the low-normal range in children born SGA, they are much higher than those observed in children with GH deficiency.

\section{The IGF System}

IGF-I and IGF-II are major regulators of pre- and postnatal growth. They circulate bound to high-affinity IGFbinding proteins (IGFBP-1 to IGFBP-6) that modulate IGF bioavailability [16]. Approximately $75 \%$ of circulating IGFs are bound in a ternary complex, consisting of IGF, IGFBP-3 and an acid-labile subunit.

Reduced circulating IGF-I levels have been reported in fetuses that are SGA and neonates born SGA, suggesting a role for IGF-I in fetal growth retardation [8, 17]. More direct evidence for a role of IGF-I in fetal and postnatal growth comes from gene deletion studies in mice. Weight and length at birth were significantly reduced in IGF-I knockout mice, and postnatally they showed a further deterioration of growth $[18,19]$. In humans, homozygous partial deletion of the gene encoding IGF-I is associated with severe impairment of pre- and postnatal growth [20]. An association has been reported between IGF-I polymorphisms and pre- and postnatal growth retardation $[21,22]$.

The importance of the intrauterine growth-promoting action of IGF-I has also been confirmed by the finding of severe IUGR and postnatal growth failure in two children with mutations in the IGF-I receptor gene [23]. In addition, infants born SGA have reduced IGFBP-3 concentrations and increased IGFBP-1 and IGFBP-2 levels [17].

Despite evidence for abnormalities in IGF levels in infants born SGA, no relationship has been found between the IGF-related variables at birth and postnatal growth $[2,8]$. In a recent cross-sectional study, we have found a correlation between the IGF-I/IGFBP-3 molar ratio in childhood and catch-up growth, expressed as actual height corrected for target height (fig. 2). The affinity of IGFBPs for IGFs may be reduced by the intervention of specific cation-dependent proteolytic enzymes (IGFBP proteases) that, by fragmenting IGFBPs, lead to an increased free IGF-I fraction and, ultimately, augmented IGF-I bioavailability. We reported the presence of two different proteases in children born SGA. One is present at birth and yields the 29-kDa form of IGFPB-3 as the major proteolytic fragment, and the second one, active at 2 months of age, produces an 18-kDa IGFBP-3 fragment [8]. The intervention of the second protease may result in increased IGF-I availability in tissues, which could lead to the postnatal catch-up growth that occurs in the first 6-12 months of life. Consistent with this, we found that the relative amount of the IGFBP-3 $18-\mathrm{kDa}$ fragment correlated with early postnatal growth [24]. 


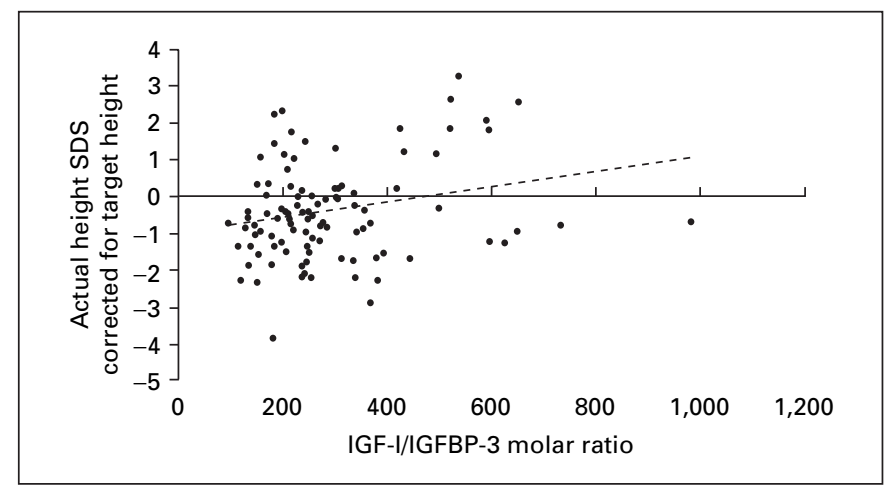

Fig. 2. Relationship between the insulin-like growth factor I (IGF-I)/IGF-binding protein-3 (IGFBP-3) molar ratio $(\times 1,000)$ and actual height corrected for target height in 98 children born small for gestational age. $\mathrm{r}=0.24, \mathrm{p}=0.01$.

Taken together, these findings suggest that the growthpromoting machinery is 'frozen' in fetuses that are SGA, probably to minimize the energy expenditure for growth and to favour the development of vital organs. During the first weeks of postnatal life, the IGF system becomes active, which allows catch-up growth in the vast majority of children born SGA.

The reported alterations in the IGF system in individuals born SGA have been observed during early postnatal life. A case-control study of older children who were born SGA did not show any significant alteration of IGF-I and IGFBP-3 levels [25]. Even after subdividing the children according to whether or not they achieved catch-up growth, we found no significant differences between the groups in the concentrations of IGF-I, IGF-II, IGFBP-1, IGFBP-3, soluble IGF-II receptor, and the relative amounts of circulating forms of IGFBP-3 produced by proteolysis [24, $25]$. This indicates that the alterations in IGF-I levels observed in neonates born SGA are transient.

\section{The Hypothalamic-Pituitary-Adrenal Axis}

The function of the hypothalamic-pituitary-adrenal axis can be permanently programmed during development [26]. In animals, exposure to glucocorticoids in prenatal and early postnatal life may imprint the hypothalamic-pituitary-adrenal axis, resulting in permanent modification of the neuroendocrine response to stress throughout life [27].

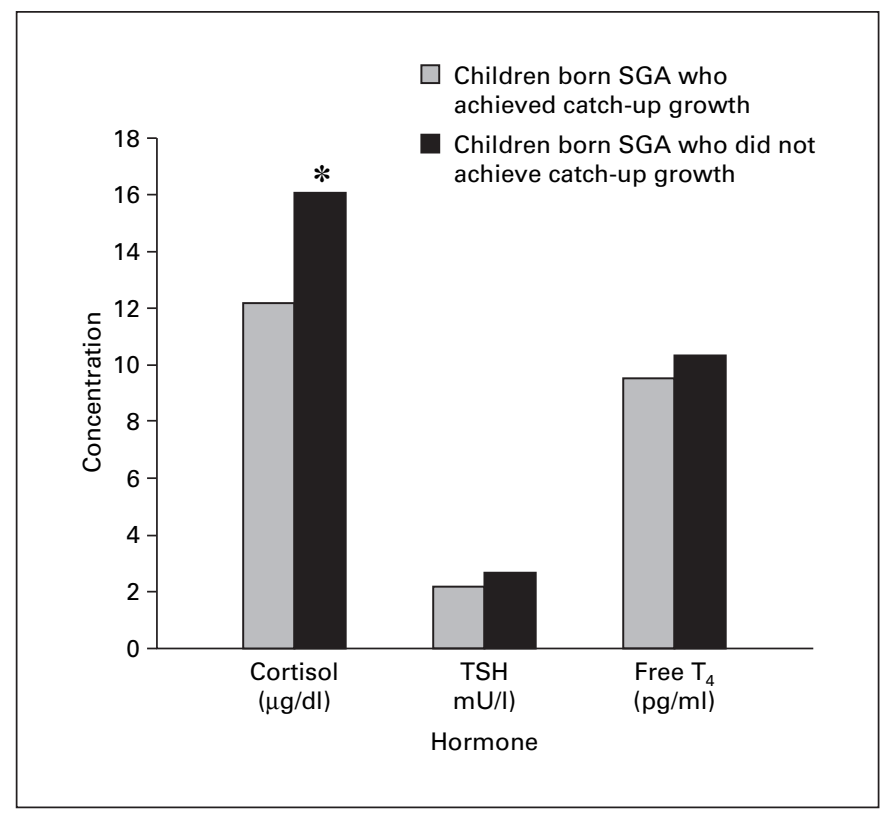

Fig. 3. Cortisol, thyrotrophin (TSH) and free thyroxine $\left(\mathrm{T}_{4}\right)$ concentrations in a case-control study of 20 children born small for gestational age (SGA) who achieved catch-up growth and 20 who did not achieve catch-up growth, matched for sex, age, pubertal status and body mass index. ${ }^{*} \mathrm{p}=0.04$ compared with those who achieved catch-up growth.

We have reported that catch-up growth in children born SGA might be affected by intrauterine programming of the hypothalamic-pituitary-adrenal axis. Preliminary results of a case-control study in 40 children born SGA (20 who achieved catch-up growth and 20 who did not), matched for sex, age (within 1 year), pubertal status and body mass index (within $0.5 \mathrm{~kg} / \mathrm{m}^{2}$ ), show that children who did not achieve catch-up growth have significantly higher fasting plasma cortisol levels than children who did achieve catch-up growth (fig. 3). Furthermore, during the neonatal period, cortisol may act by limiting IGFBP-3 proteolysis, thus reducing IGF bioavailability and ultimately leading to early growth impairment [24].

\section{Thyroid Function}

Reductions in circulating concentrations of free thyroxine and free tri-iodothyronine and a modest elevation in concentrations of thyrotrophin (TSH) have been reported in fetuses with IUGR [28]. A significant reduction in the expression of isoforms of the thyroid receptor in the human fetal nervous system during IUGR has also been 
described [29]. We previously reported that children born SGA who do not show postnatal catch-up growth have higher, though normal, TSH concentrations than individuals born SGA who do achieve catch-up growth [25].

Recently, abnormal thyroid function has been found in children born SGA when compared with children born at a weight appropriate for gestational age [30]. Amazingly, up to $20 \%$ of the children born SGA showed TSH serum levels above the upper limit of normality. However, it has to be pointed out that most of the children born SGA studied by Radetti and co-workers were born preterm. In our recent case-control study, we did not find any significant difference in thyroid function between children born SGA at term with or without postnatal catch-up growth (fig. 3).

\section{Conclusion}

IGF-I is a major determinant of prenatal and early postnatal growth, as demonstrated in animal models and humans born with genetic abnormalities of the IGF system. Neonates born SGA show transient alterations of the
GH-IGF-I axis and IGF system, probably reflecting the in utero endocrine pattern. In infancy and childhood, IGF-I and IGFBP-3 concentrations are in the low-normal range and $\mathrm{GH}$ responses to stimulation tests are normal, although subtle alterations of spontaneous GH secretion have been described.

There is evidence suggesting that the hypothalamicpituitary-adrenal axis and thyroid function may regulate pre- and postnatal growth in children born SGA, at least in early life. However, data are still conflicting, probably due to the different assessment methods used and the different populations studied.

Whilst no endocrine parameter seems to be a reliable predictor of the linear growth outcome, the major predictors of height in children born SGA are birth length, target height and body mass index.

\section{Acknowledgements}

This work was supported in part by Ministero dell'Istruzione dell'Università e della Ricerca Grant COFIN 40\%-2003064547.

\section{References}

1 Karlberg J, Albertsson-Wikland K: Growth in full-term small-for-gestational-age infants: from birth to final height. Pediatr Res 1995;38: 733-739.

-2 Leger J, Noel M, Limal JM, Czernichow P: Growth factors and intrauterine growth retardation. II. Serum growth hormone, insulin-like growth factor (IGF) I, and IGF-binding protein 3 levels in children with intrauterine growth retardation compared with normal control subjects: prospective study from birth to two years of age. Study Group of IUGR. Pediatr Res 1996;40:101-107.

$\checkmark 3$ Hokken-Koelega AC, De Ridder MA, Lemmen RJ, Den Hartog H, De Muinck KeizerSchrama SM, Drop SL: Children born small for gestational age: do they catch up? Pediatr Res 1995;38:267-271.

$\checkmark 4$ Leger J, Limoni C, Collin D, Czernichow P: Prediction factors in the determination of final height in subjects born small for gestational age. Pediatr Res 1998;43:808-812.

$\checkmark 5$ Luo ZC, Albertsson-Wikland K, Karlberg J: Length and body mass index at birth and target height influences on patterns of postnatal growth in children born small for gestational age. Pediatrics 1998;102:E72.
$>6$ Deiber M, Chatelain P, Naville D, Putet G, Salle B: Functional hypersomatotropism in small for gestational age (SGA) newborn infants. J Clin Endocrinol Metab 1989;68:232234.

$>7$ de Zegher F, Kimpen J, Raus J, Vanderschueren-Lodeweyckx M: Hypersomatotropism in the dysmature infant at term and preterm birth. Biol Neonate 1990;58:188-191.

$>8$ Cianfarani S, Germani D, Rossi P, Rossi L, Germani A, Ossicini C, Zuppa A, Argiro G, Holly JM, Branca F: Intrauterine growth retardation: evidence for the activation of the insulin-like growth factor (IGF)-related growthpromoting machinery and the presence of a cation-independent IGF binding protein-3 proteolytic activity by two months of life. Pediatr Res 1998;44:374-380.

$>9$ Grunt JA, Howard CP, Daughaday WH: Comparison of growth and somatomedin $\mathrm{C}$ responses following growth hormone treatment in children with small-for-date short stature, significant idiopathic short stature and hypopituitarism. Acta Endocrinol (Copenh) 1984; 106:168-174.

$>10$ Ackland FM, Stanhope R, Eyre C, Hamill G, Jones J, Preece MA: Physiological growth hormone secretion in children with short stature and intra-uterine growth retardation. Horm Res 1988;30:241-245.
11 de Waal WJ, Hokken-Koelega AC, Stijnen T, de Muinck Keizer-Schrama SM, Drop SL: Endogenous and stimulated $\mathrm{GH}$ secretion, urinary $\mathrm{GH}$ excretion, and plasma IGF-I and IGF-II levels in prepubertal children with short stature after intrauterine growth retardation. The Dutch Working Group on Growth Hormone. Clin Endocrinol (Oxf) 1994;41:621630 .

12 Boguszewski M, Rosberg S, Albertsson-Wikland K: Spontaneous 24-hour growth hormone profiles in prepubertal small for gestational age children. J Clin Endocrinol Metab 1995;80: 2599-2606.

$>13$ Thieriot-Prevost G, Boccara JF, Francoual C, Badoual J, Job JC: Serum insulin-like growth factor 1 and serum growth-promoting activity during the first postnatal year in infants with intrauterine growth retardation. Pediatr Res 1988;24:380-383.

14 Van den Berghe G, de Zegher F: Anterior pituitary function during critical illness and dopamine treatment. Crit Care Med 1996;24:15801590.

15 de Zegher F, Francois I, van Helvoirt M, Van den Berghe G: Clinical review 89: Small as fetus and short as child: from endogenous to exogenous growth hormone. J Clin Endocrinol Metab 1997;82:2021-2026. 
16 Jones JI, Clemmons DR: Insulin-like growth factors and their binding proteins: biological actions. Endocr Rev 1995;16:3-34.

17 Giudice LC, de Zegher F, Gargosky SE, Dsupin BA, de las Fuentes L, Crystal RA, Hintz RL, Rosenfeld RG: Insulin-like growth factors and their binding proteins in the term and preterm human fetus and neonate with normal and extremes of intrauterine growth. J Clin Endocrinol Metab 1995;80:1548-1555.

$\checkmark 18$ Baker J, Liu JP, Robertson EJ, Efstratiadis A: Role of insulin-like growth factors in embryonic and postnatal growth. Cell 1993;75:7382.

19 Wang J, Zhou J, Powell-Braxton L, Bondy C: Effects of Igf1 gene deletion on postnatal growth patterns. Endocrinology 1999;140: 3391-3394.

-20 Woods KA, Camacho-Hubner C, Savage MO, Clark AJ: Intrauterine growth retardation and postnatal growth failure associated with deletion of the insulin-like growth factor I gene. N Engl J Med 1996;335:1363-1367.

21 Arends N, Johnston L, Hokken-Koelega A, van Duijn C, de Ridder M, Savage M, Clark A: Polymorphism in the IGF-I gene: clinical relevance for short children born small for gestational age (SGA). J Clin Endocrinol Metab 2002;87:2720-2724.
22 Johnston LB, Dahlgren J, Leger J, Gelander L, Savage MO, Czernichow P, Wikland KA, Clark AJ: Association between insulin-like growth factor I (IGF-I) polymorphisms, circulating IGF-I, and pre- and postnatal growth in two European small for gestational age populations. J Clin Endocrinol Metab 2003;88:48054810.

23 Abuzzahab MJ, Schneider A, Goddard A, Grigorescu F, Lautier C, Keller E, Kiess W, Klammt J, Kratzsch J, Osgood D, Pfaffle R, Raile K, Seidel B, Smith RJ, Chernausek SD: IGF-I receptor mutations resulting in intrauterine and postnatal growth retardation. N Engl J Med 2003;349:2211-2222.

4 Cianfarani S, Geremia C, Scott CD, Germani D: Growth, IGF system, and cortisol in children with intrauterine growth retardation: is catch-up growth affected by reprogramming of the hypothalamic-pituitary-adrenal axis? Pediatr Res 2002;51:94-99.

25 Cianfarani S, Maiorana A, Geremia C, Scire G, Spadoni GL, Germani D: Blood glucose concentrations are reduced in children born small for gestational age (SGA), and thyroidstimulating hormone levels are increased in SGA with blunted postnatal catch-up growth. J Clin Endocrinol Metab 2003;88:26992705 .
6 Levine S: Maternal and environmental influences on the adrenocortical response to stress in weanling rats. Science 1967;156:258-260

-27 Dodic M, Peers A, Coghlan JP, Wintour M: Can excess glucocorticoid, predispose to cardiovascular and metabolic disease in middle age? Trends Endocrinol Metab 1999;10:8691.

28 Kilby MD, Verhaeg J, Gittoes N, Somerset DA, Clark PM, Franklyn JA: Circulating thyroid hormone concentrations and placental thyroid hormone receptor expression in normal human pregnancy and pregnancy complicated by intrauterine growth restriction (IUGR). J Clin Endocrinol Metab 1998;83: 2964-2971.

29 Kilby MD, Gittoes N, McCabe C, Verhaeg J, Franklyn JA: Expression of thyroid receptor isoforms in the human fetal central nervous system and the effects of intrauterine growth restriction. Clin Endocrinol (Oxf) 2000;53: 469-477.

30 Radetti G, Renzullo L, Gottardi E, D'Addato $\mathrm{G}$, Messner H: Altered thyroid and adrenal function in children born at term and preterm, small for gestational age. J Clin Endocrinol Metab 2004;89:6320-6324. 